in vivo $34: 3387-3398(2020)$

doi:10.21873/invivo.12177

\title{
Treatment Outcome of the Combination Therapy of High-dose rate Intracavitary Brachytherapy and Intensity-modulated Radiation Therapy With Central-shielding for Cervical Cancer
}

\author{
YUKI MUKAI $^{1,2}$, YUMIKO MINAGAWA ${ }^{2}$, HIROMI INOUE $^{3}$, AKIKO SATO $^{1}$, KENGO MATSUI $^{2}$, \\ TAKANORI FUKUDA ${ }^{3}$, KAZUYA ONUMA $^{3}$, HIDEYUKI HONGO $^{2}$, RYOSUKE SHIRATA $^{2}$, HIRONORI NAGATA $^{2}$, \\ HARUMITU HASHIMOTO ${ }^{4}$, TOMIO INOUE ${ }^{5}$, MASAHARU HATA $^{1}$ and MOTOKO OMURA ${ }^{2}$ \\ ${ }^{1}$ Department of Radiation Oncology, Yokohama City University Graduate School of Medicine, Yokohama, Japan; \\ ${ }^{2}$ Department of Radiation Oncology, Shonan Kamakura General Hospital, Kamakura, Japan; \\ ${ }^{3}$ Department of Obstetrics and Gynecology, Shonan Kamakura General Hospital, Kamakura, Japan; \\ ${ }^{4}$ Department of Radiation Oncology, Shonan Fujisawa Tokushukai Hospital, Fujisawa, Japan; \\ ${ }^{5}$ Department of Advanced Medical Center, Shonan Kamakura General Hospital, Kamakura, Japan
}

\begin{abstract}
Background/Aim: This study aimed to evaluate the clinical outcome of intensity-modulated radiation therapy (IMRT) and high-dose-rate intracavitary brachytherapy (HDR-ICBT) in uterine cervical cancer (UCC). IMRT consisted of whole-pelvic radiation therapy (WPRT) and sequential WPRT with central-shielding (WPRT-CS). Patients and Methods: Thirty UCC patients treated with IMRT using TomoTherapy, were retrospectively analyzed. Results: The median dose of WPRT and WPRT-CS was 36 and $14.4 \mathrm{~Gy}$ and the median total dose of these was $50 \mathrm{~Gy}$ in 25 fractions $(\mathrm{Fr})$. Median HDR-ICBT dose/Fr to Point A was $25 \mathrm{~Gy} / 5 \mathrm{Fr}$. Median 2 Gy per fraction-equivalent dose (EQD2) of combined WPRT and HDR-ICBT to Point A $(\alpha / \beta=10)$ was $71.0 \mathrm{~Gy}$. The 3-year local control, disease-free survival, and overall survival rates were $89.9 \%, 83.3 \%$, and 86.3\%. Conclusion: IMRT of WPRT and WPRT-CS given in combination with HDR-ICBT was a feasible therapy resulting in good disease control and tolerance in patients with $U C C$.
\end{abstract}

This article is freely accessible online.

Correspondence to: Yuki Mukai, MD (ORCID number: 0000-00020000-1199), Department of Radiation Oncology, Yokohama City University Graduate School of Medicine, Kanazawa-ku, Yokohama, Kanagawa 236-0004, Japan. Tel: +81 457872800, Fax: +81 457860369, e-mail: y_mukai@yokohama-cu.ac.jp

Key Words: Uterus cervical cancer, high-dose rate intracavitary brachytherapy, intensity-modulated radiation therapy, whole pelvic radiation therapy, central shielding.
With recent increases in the rate of uterine cervical cancer (UCC) in Japan, the role of radiation therapy (RT) in this disease has become more important. Standard RT for UCC includes the combination of external beam radiation therapy (EBRT) to whole pelvis (WP) using three-dimensional conformal radiation therapy (3D-CRT) and high-dose-rate intracavitary brachytherapy (HDR-ICBT) (1-3). Several recent reports have described the use of intensity-modulated radiation therapy (IMRT) for WPRT instead of 3D-CRT (47). This strategy appears to provide excellent dose distribution and fewer acute adverse effects compared with 3D-CRT (4, 8-11). In Western countries, 45-50 Gy of WPRT followed by HDR-ICBT is recommended as standard therapy for UCC. However, Asian women typically have a smaller physique than Caucasian women and may have a smaller uterus and vagina surrounded by a thinner layer of fatty tissue. It can be challenging to maintain sufficient space between the HDR-ICBT source and rectal wall during treatment for UCC, resulting in excess exposure to the rectum. Therefore, in Japan and in other Asian countries, standard EBRT includes the combination of WPRT and sequential WPRT with central shielding (WPRT-CS) to avoid overexposure of the rectum in advance of HDR-ICBT. In 3D-CRT, CS comprises a simple rectangular midline block of $4 \mathrm{~cm}$ in width, formed by multi-leaf collimators (MCL) $(12,13)$.

In the present study, we applied IMRT consisting of WPRT and WPRT-CS instead of 3D-CRT for the treatment of patients with UCC and evaluated the feasibility, treatment outcome, and tolerance of this strategy. To our knowledge, this is the first report of the combination of WPRT and WPRT-CS using IMRT. 
Table I. Patient and treatment related characteristics.

\begin{tabular}{lc}
\hline Age (years), median (range) & $64(38-91)$ \\
Primary tumor size/diameter (mm), & $46(10-70)$ \\
median (range) & \\
Performance status (n) & 22 \\
0 & 7 \\
1 & 1 \\
2 & \\
Histopathology (n) & 25 \\
SCC & 1 \\
Adenocarcinoma & 2 \\
Mucinous adenocarcinoma & 1 \\
Papillary adenocarcinoma & 1 \\
Carcinoma & \\
FIGO 2008 & 6 \\
IB & 2 \\
IIA & 13 \\
IIB & 1 \\
IIIA & 7 \\
IIIB & 1 \\
IVA & \\
Regional lymph node metastases & 15 \\
Positive & 15 \\
Negative & \\
\hline
\end{tabular}

SCC: Squamous cell carcinoma; FIGO: international federation of gynecology and obstetrics.

\section{Patients and Methods}

Between August 2011 and October 2016, 30 consecutive UCC patients were treated with IMRT using TomoTherapy followed by HDR-ICBT in our institution. Patients intended for treatment with curative intent were eligible for participation in this study. They underwent a workup including basic laboratory studies, contrastenhanced computed tomography (CT) scans of the neck to the pelvis, and magnetic resonance imaging (MRI) of the pelvis, and all tumors were histopathologically confirmed. In addition, some patients underwent whole-body positron emission tomography (PET/CT). Patients were stratified according to the International Federation of Gynecology and Obstetrics (FIGO) 2008 staging system. The disease characteristics of the 30 patients are summarized in Table I. This study was approved by the review board of our institution (TGE01116-024), and informed consent was obtained from all patients.

Radiation therapy. Prior to the planning CT, patients were instructed to drink an appropriate amount of water to maintain an almost-full bladder. Their bladder volume was measured and recorded using BLADDERSCAN ${ }^{\circledR}$ (Verathon Inc., Bothell, WA, USA). Patients were also asked to ensure an empty rectum at the time of planning CT. When necessary, patients received appropriate laxative medication to achieve this. Axial images of 2-mm slice thickness were acquired using an 8-row multi-detector CT (Light Speed, GE, USA) or 64-row multi-detector CT (Siemens, Forchheim, Germany). Previously acquired contrast-enhanced CT images and MR images were fused to the original plain CT images using the Pinnacle $^{3}$ treatment planning system (Version 9.2, Philips Medical Systems, Fitchburg, WI, USA) to delineate the targets.
Table II. The planning goals for target volumes in WPRT planning

\begin{tabular}{|c|c|}
\hline \multicolumn{2}{|l|}{ Definition } \\
\hline GTV & Primary tumors, involved lymph nodes \\
\hline CTV for parametrium & According to published guidelines (13-160) \\
\hline $\begin{array}{l}\text { CTV for lymph nodes } \\
\text { regions }\end{array}$ & $\begin{array}{l}\text { The common, external, internal iliac, } \\
\text { obturator, pre-sacral lymph nodal regions } \\
\text { [according to published guidelines (14)] }\end{array}$ \\
\hline PTV for tumor & $\mathrm{GTV}+1-\mathrm{cm}$ \\
\hline $\begin{array}{l}\text { PTV for involved } \\
\text { lymph node }\end{array}$ & $\mathrm{GTV}+5-\mathrm{mm}$ \\
\hline PTV for lymph node & $\mathrm{CTV}+5-\mathrm{mm}$ \\
\hline PTV for parametrium & $\mathrm{CTV}+5-\mathrm{mm}$, except for the anterior, $+7-\mathrm{mm}$ \\
\hline PTV for uterus & $\begin{array}{l}\text { The entire uterus }+5-\mathrm{mm} \text {, except for the } \\
\text { anterior, }+7-\mathrm{mm}\end{array}$ \\
\hline PTV for vagina & The entire vagina $+5-\mathrm{mm}$ \\
\hline
\end{tabular}

Planning goals for Target volume

\begin{tabular}{ll}
\hline PTV D50 & Prescribed dose $(50.4 \mathrm{~Gy})$ \\
PTV D95 & $>95 \%$ of the prescribed dose \\
GTV D97-99 & Prescribed dose $(50.4 \mathrm{~Gy})$
\end{tabular}

GTV: Gross tumor volume; CTV: clinical target volume; WPRT: whole pelvic radiation therapy; PTV: planning target volume.

Table III. The dose constraints for OARs in WPRT planning.

Constraints for OARs

\begin{tabular}{ll}
\hline Femoral head & Maximum dose $<50 \mathrm{~Gy}$ \\
Bowel space & V40 Gy $<37 \%$ \\
Bladder & as low as possible \\
Rectum & as low as possible \\
Sigmoid loop & as low as possible \\
Body & Maximum dose $<110 \%$ of the prescribed dose \\
\hline
\end{tabular}

OARs: Organs at risk.

Contours for targets and organs at risk (OARs) were drawn using the Pinnacle 3 system. The definition of the gross tumor volume (GTV), clinical target volume (CTV), and planning target volume (PTV) are shown in Tables II and III, and CTV for pelvic lymph nodes (LN) and parametrium was delineated according to published guidelines (14-17). The presacral region typically included $1 \mathrm{~cm}$ of tissue anterior to the S1, S2 and S3 sacral segments of soft tissue. The lower pre-sacral nodes were included if there was tumor extension along the uterosacral ligaments, rectal involvement, or lymph-node metastasis/involvement. In these cases, the entire mesorectal space was also included in the CTV. Both PTV uterus and PTV parametrium included each CTV plus a 5-mm uniform margin, except for anteriorly, where a 7-mm margin was added with consideration to the inter-fractional variations of bladder volume. The upper and lower borders of all PTVs in a typical case were L4L5 and a transverse line below the obturator foramen, respectively, depending on tumor invasion. Bowel space was contoured according to RTOG (radiation therapy oncology group) 1203 criteria (18). 
Treatment plans were generated using Hi-Art system TomoTherapy inverse planning software based on superposition dose calculation (Figure 1A and B). A field width of $2.5 \mathrm{~cm}$ and a pitch of 0.43 were applied, and the modulation factor was mainly in the range of 1.5-2.0. In general, the total prescribed dose of WPRT and WPRTCS was 50-50.4 Gy. The fraction size was 1.8 or $2.0 \mathrm{~Gy}$ for patients treated with or without chemotherapy, respectively.

The planning goals for target volumes and the dose constraints for OARs are summarized in Tables II and III. Updated CT and MRI images were acquired immediately before the delivery of WPRT-CS and used to create the treatment plan. First, updated PTVs were delineated in the same manner as for initial WPRT. Next, CS was defined as a 4-cm wide structure in the center of PTV, as shown in Figure 1C. Three nested virtual structures were established within the CS by contracting its outline in 5-mm steps. The dose constraints of these nested structures were gradually restricted to reduce the dose within the center of CS to as low as possible. The PTV for WPRT excluding the volume of CS was defined as the PTV for WPRT-CS. The lower, anterior, and posterior borders of WPRT-CS were the same as those of the PTVs for WPRT.

As is the case with planning CT, patients drank an appropriate amount of water to maintain an almost-full bladder, and bladder volume was measured using BLADDERSCAN ${ }^{\circledR}$. Image-guided radiation therapy (IGRT) using megavolt CT (MVCT) is performed in every fraction of radiation therapy. With the TomoTherapy system, daily MVCT image registration with treatment-planning CT is essential for RT. Uterus, bladder, and rectum can be recognized using MVCT.

The levels of IGRT in this study corresponded to/were equivalent to Intermediate-IGRT according to EMBRACEs definition (19).

The schedule for IMRT and HDR-ICBT is shown in Figure 2. The fraction ratio of WPRT and WPRT-CS was determined according to tumor volume reduction during WPRT as well as in accordance with Japanese treatment guidelines for UCC (20). In most patients, WPRT was performed until the day before the first HDR-ICBT administration, and WPRT-CS started on the day after. HDR-ICBT was performed once per week during the treatment period of IMRT, and twice a week after its completion where possible. HDR-ICBT was performed using Ir-192 afterloading machines (microSelectron-HDR, Nucletron, the Netherlands; or MultiSource, Eckert \& Ziegler BEBIG, Berlin, Germany). For HDR-ICBT, a combination of tandem and ovoid applicators using the Manchester system were applied. The standard regimen of HDR-ICBT in our institution was 5 Gy per fraction for Point A using 2D planning $(12,13,21,22)$. Total dose and fractions of HDR-ICBT were determined in consideration of the total biological effective dose (BED) to the rectum in WPRT and HDR-ICBT. That of WPRT was calculated using the dose to the anterior portion of the rectum, which was equivalent to the prescribed dose. In addition, that of WPRT-CS was not taken into consideration. The BED of HDR-ICBT was calculated at rectal reference points (RP) as defined in the International Commission on Radiation Units and Measurements Report 38 (ICRU 38) (defined as the most anterior portion of the rectum). In reference to a previous report (3), we set a limit of total BED 3 [BED $(\alpha / \beta=3)]$ to the rectum for WPRT and HDRICBT to be within the first half of 130 and at least less than 140 . HDR-ICBT was delivered up to a dose of 25 Gy in 5 fractions unless the total BED 3 for the rectum exceeded the criteria mentioned above.
Evaluation criteria and statistical analysis. Our institutional standard follow-up visits were carried out at the Department of Gynecology and Radiation Oncology to assess treatment outcome and toxicities. They included physical examination, Papanicolaou smears (Pap smears), tumor marker assessment, and imaging studies using echography approximately every 3 months in the first 1-2 years of follow-up, and every 6 months thereafter. Imaging studies using CT were performed annually. Toxicities associated with treatment were evaluated using the Common Terminology Criteria for Adverse Events v4.0. Acute toxicities were defined as therapyrelated adverse events that occurred within 3 months after the beginning of treatment, and late toxicities as those occurring after that. The overall survival (OS) rate, disease-free survival (DFS) rate, and local recurrence (LC) rate from the beginning of treatment were calculated using Kaplan-Meier curves. The differences between curves were evaluated by log-rank testing using SPSS for Windows software, version 23.0 (IBM institute, Armonk, NY, USA). A pvalue $<0.05$ was considered statistically significant.

\section{Results}

All 30 patients completed the treatment series of WPRT, WPRT-CS, and HDR-ICBT. The median follow-up time was 38.5 months (range=4-87 months). The median duration of all treatments was 53 days (range $=39-64$ days). Twenty-one $(70 \%)$ of patients completed all treatments within 8 weeks, as recommended by the American Brachytherapy Society (23). The prescribed doses are summarized in Table IV. The total dose of WPRT and WPRT-CS was 50-50.4 Gy in 25-28 fractions (Fr). In three patients, WPRT-CS was not applied because of insufficient cervical tumor reduction for intracavitary application of HDR-ICBT after 40 Gy of WPRT. In the remaining 27 patients, the median total dose of WPRT and WPRT-CS was 36 Gy (range=20-41.4 Gy) and 14.4 Gy (range=9-28 Gy), respectively. Median 2 Gy per fraction-equivalent dose (EQD2) of combined WPRT and HDR-ICBT to Point $A(\alpha / \beta=10)$ and to the rectum $(\alpha / \beta=3)$ was 71.0 Gy (range=57.74-82.56 Gy) and 65.4 Gy (range=56.96-72.9 Gy), respectively. For the rectum, median total BED 3 of WPRT and HDR-ICBT was 115.1 (range=67.4-136.1, median total equivalent dose (EQD2) was 68.9). In 6 patients, the total BED 3 was $>130$.

Chemotherapy. Chemotherapy was administered to 22 of the 30 patients $(73.3 \%)$ in 2-6 courses, with a median of 5 courses. For the remaining 8 patients, chemotherapy was not administered for the following reasons: advanced age ( $>80$ years old, $n=5$ ), poor performance status (PS) $(n=4)$, renal dysfunction $(n=1)$, small tumor size $(n=1$, stage Ib1), multiple myositis $(n=1)$, and patient refusal $(n=1)$. For some patients, there was more than one reason that chemotherapy was not administered.

Disease control. Figure 3 shows the Kaplan-Meier curves for LC, DFS, and OS. Twenty-five of the 30 patients presented as disease-free $(83.3 \%)$ at the final evaluation. Three-year 


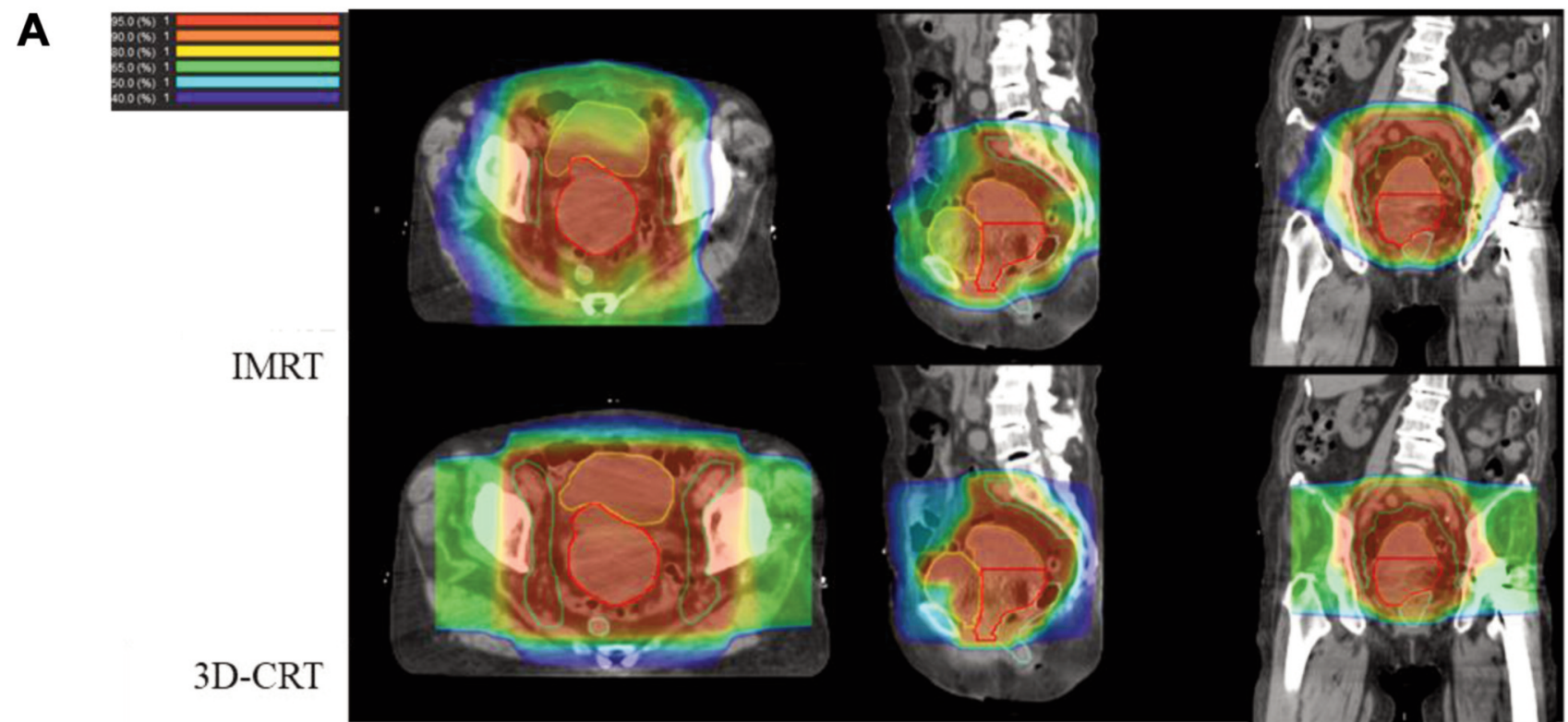

B

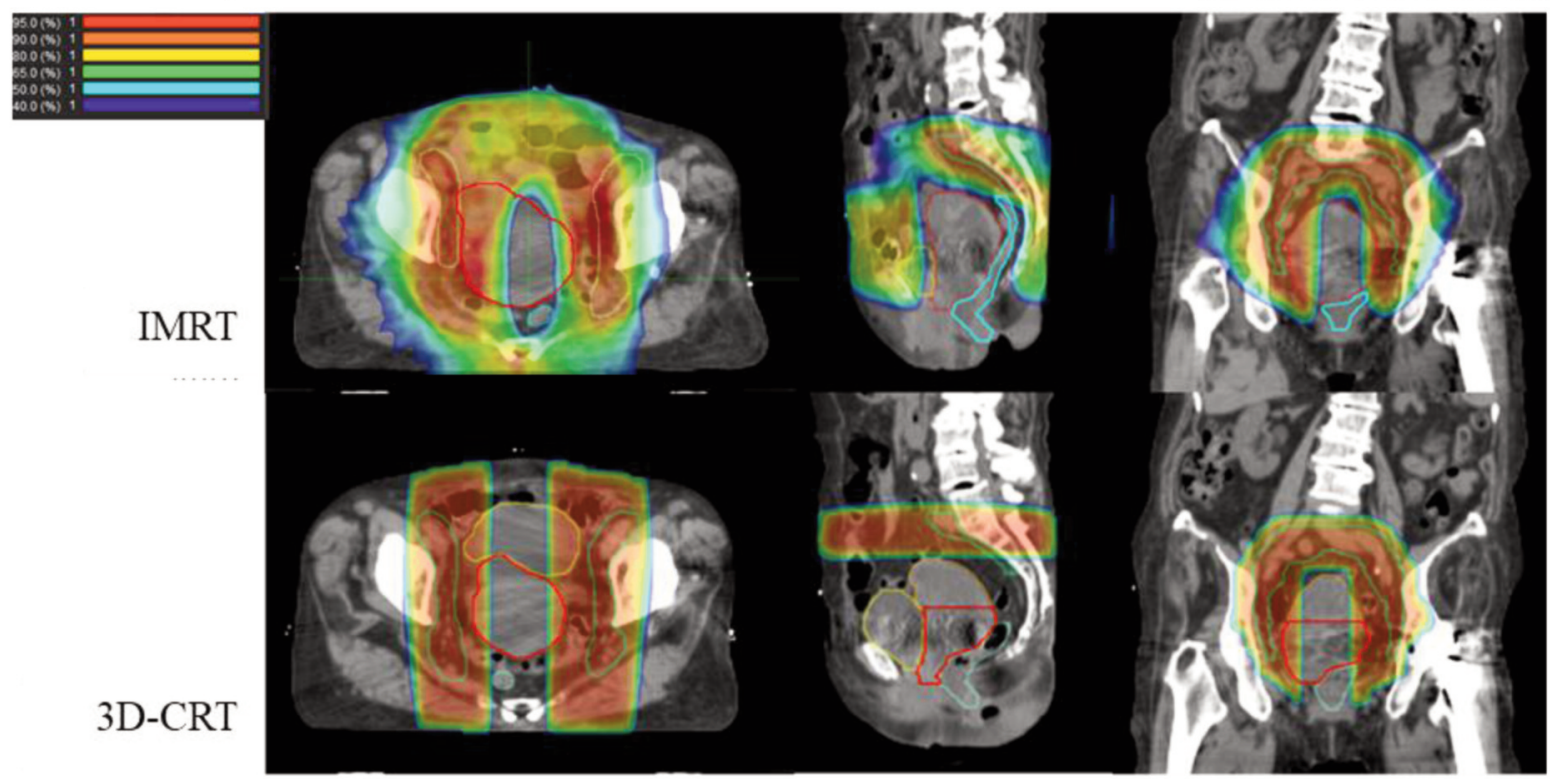

Figure 1. Continued

LC, DFS, and OS rates for the entire cohort were $89.9 \%$ $(95 \% \mathrm{CI}=0.729-0.967), 83.3 \% \quad(95 \% \mathrm{CI}=0.657-0.929)$, and $86.3 \%(95 \% \mathrm{CI}=0.620-0.923)$, respectively. Of all 30 patients, 6 experienced disease progression, and the patterns of progression are shown in Table V. In summary, 4 patients (cases 1-4) died of metastatic disease. There were two patients with mucinous adenocarcinoma in this study, and both of them had progression of the disease (cases 2 and 4). One patient (case 5) developed local progression without any evidence of metastatic disease. She developed a uterorectal fistula 2 months after initial treatment. She was alive with disease at the time of the final evaluation. Case 6 developed para-aortic lymph node metastasis 5 years after initial therapy. She also received 60 Gy in 30 fractions of RT to the paraaortic lesion. She was disease-free at the last follow-up visit.

Treatment tolerance. Table VI shows treatment-related acute and late toxicities. All acute toxicities were tolerable/manageable, and no patient had $\geq$ Grade 3 excluding hematology toxicity (HT). Nine patients took $>56$ days to complete their treatment because they experienced Grade 3 HT. All cases of HT resolved after treatment. Treatment-related $\geq$ Grade 2 late gastrointestinal (GI) toxicities were observed in 2 patients $(6.6 \%)$. One patient had viscous stool 7 months after treatment. The other patient had 


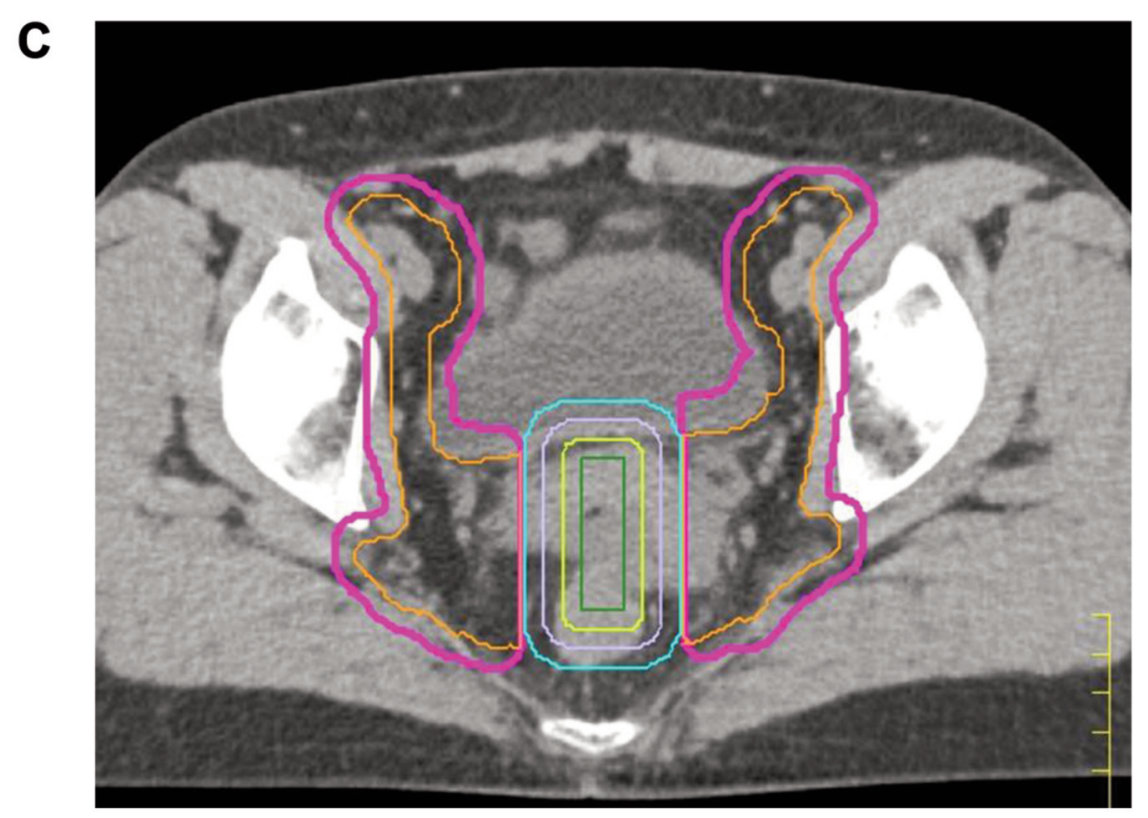

Figure 1. Representative dose distribution of WPRT and WPRT-CS field in IMRT and 3D-CRT. A) WP field in IMRT (upper) and 3D-CRT (lower). B) WP-CS field in IMRT (upper) and 3D-CRT (lower). Red line: tumor; Yellow line: bladder; Light blue line: rectum. 3D-CRT plan was made for the planning study to compare the dose distribution to that of the IMRT plan. C) Central shielding. The central shielding (CS, light blue line) was defined as a 4-cm wide structure in the center of PTV 3 (pink line). Three nested virtual structures (light violet line, light green line, and green line) were established within the CS by contracting its outline in 5-mm steps. WPRT: Whole pelvic radiation therapy; WPRT-CS: WPRT with central shielding; IMRT: intensity-modulated radiation therapy; 3D-CRT: three-dimensional conformal radiation therapy.

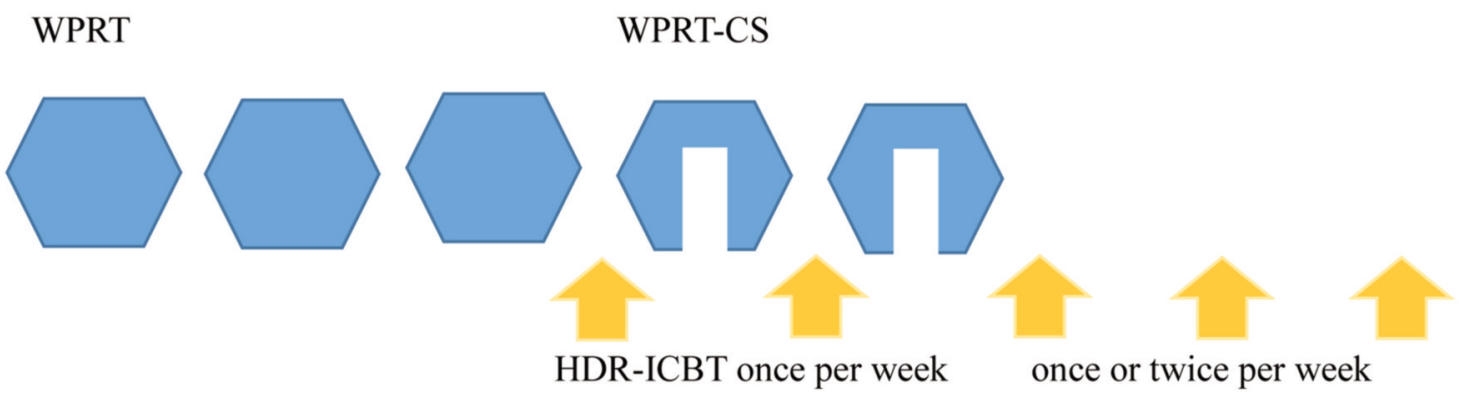

Figure 2. The representative schedule of the IMRT and HDR-ICBT. After WPRT and sequential WPRT CS, the HDRT ICBT was delivered once or twice per week. IMRT: Intensity-modulated radiation therapy; WPRT: whole pelvic radiation therapy 5; WPRT-CS: whole pelvic radiation therapy with central shielding 6; HDR-IBCT: high dose rate intra cavity brachytherapy.

rectal hemorrhage 11 months after treatment and had argon plasma coagulation 17 months after her symptoms started. Their symptoms disappeared after medication. There was no genitourinary (GU) late toxicity, and no other severe late toxicities ( $\geq$ Grade 3 ) associated with treatment.

Statistical analysis. The 3-year OS and DFS were significantly better in patients with the following characteristics; pathology status of squamous cell carcinoma (OS; $p=0.035$, DFS; $p=0.015), \geq 50$ years old at diagnosis (OS; $p=0.006$, DFS; $p=0.013)$, and pretreatment hemoglobin level $\geq 7 \mathrm{~g} / \mathrm{dl}$ (OS; $p=0.006$, DFS; $p=0.013$ ). Treatment time $>56$ days did not significantly affect OS, DFS, or LC; neither did any of the following factors: presence of lymph node metastasis, clinical stage (FIGO stage $>$ II), tumor diameter $>4 \mathrm{~cm}$, chemotherapy, or application of WPRT-CS.

\section{Discussion}

The aim of this study was to evaluate the feasibility, treatment outcome, and tolerance of the combination of IMRT with HDR-ICBT. The characteristic of our study was 
the application of IMRT, which consisted of WPRT and WPRT-CS, to UCC. WPRT-CS was usually applied in Asian women who typically have a smaller physique than Western women. Some studies to date have presented treatment outcomes of the definitive RT for UCC patients using Helical TomoTherapy as well as other IMRT modalities $(1,2,8,24$, 25). However, none of these studies applied WPRT-CS, given that they enrolled patients in Western countries. Tamaki et al. reported a dosimetric analysis of WPRT-CS using VMAT for UCC as a planning study (26). To the best of our knowledge, this is the first report of the combination of HDR-ICBT and IMRT, which consisted of WPRT and WPRT-CS using TomoTherapy or other IMRT modalities, for UCC patients in clinical practice.

Comparison with other IMRT studies (outcomes and toxicities). Table VII shows the treatment outcomes of definitive RT for UCC using TomoTherapy or other IMRT methods. Application of CS reduced the dose to the rectum as well as to the GTV of the primary tumor. In addition, the delivery dose of HDR-ICBT in the present study was relatively lower than that in other studies. As shown in Table VII, the OS and LC of our patients were comparable with those of patients receiving other IMRT modalities without WPRT-CS. In the present study, the incidence of acute and late GI and GU toxicities was comparable with those of previous IMRT studies of WPRT and HDR-ICBT (4, 7-11, 25-28).

Comparison with 3D-CRT studies (outcomes and toxicities). The clinical outcome of the present study was also comparable with that of 3D-CRT using WPRT-CS (Table VII). In previous reports of WPRT and WPRT-CS for UCC applied by 3D-CRT, the late GI and GU toxicity rate was $20 \%-30 \%(13,29-31)$. In our study, the rate of late Grade 2 toxicity was only $6.6 \%$, and no patients developed Grade 3 or 4 toxicities. It was presumed that the TomoTherapy technique reduced the dose distribution to the bladder, colon, and intestine in WPRT and WPRT-CS, leading to a lower incidence of GI and CU toxicities than that seen with 3D-CRT. In addition, as previously stated, we strictly set the limit for total BED3 of WPRT and HDRICBT for the rectum to be within the first half of 130 and at least $<140$, according to criteria proposed by Ogino et al. (3). These careful considerations/attentions to reduce the dose of OARs may have led to the low incidence of GI and GU toxicities. In further studies, it will be necessary to evaluate dose delivery to OARs using TomoTherapy compared with 3D-CRT.

An advantage of WPRT-CS using TomoTherapy was that, compared with 3D-CRT, sufficient dose was delivered to the pre-sacral lymph node area, while that to the bladder and rectum was suppressed (Figures 1 and 2). However, one disadvantage was that the maximum dose to the anterior wall
Table IV. Prescribed doses and chemotherapy of the 30 patients.

\begin{tabular}{lc}
\hline RT sequence/schedules & Median (range) \\
\hline Total WPRT+WPRT-CS & $50.4(45-50.4) \mathrm{Gy}$ \\
WPRT/WPRT-CS $(\mathrm{n}=27) *$ & $36.0(20-41.4) \mathrm{Gy} / 14.4(9-28) \mathrm{Gy}$ \\
Involved lymph nodes & $54(53.6-60) \mathrm{Gy}$ \\
HDR-ICBT & $25(15-30) \mathrm{Gy}$ in $5(3-5)$ fractions \\
\hline $\begin{array}{l}\text { Dose to Point A }\left(\mathrm{EQD} 2(\alpha / \beta=10)^{* * *}\right. \\
\text { Rectum EQD2 }(\alpha / \beta=3), \\
(\text { WPRT+HDR-ICBT) }\end{array}$ & $65.4($ range=56.96-72.9) Gy \\
\end{tabular}

*In the remaining 3 patients, $50.4 \mathrm{~Gy}$ of WPRT but not WPRT-CS was applied. **Dose to Point A (EQD2 $(\alpha / \beta=10)$ of WPRT+HD-ICBT). RT: Radiation therapy; WPRT: whole pelvic radiation therapy; WPRT-CS: whole pelvic radiation therapy-central shielding; HDR-ICBT: high dose intra-cavity brachytherapy; EQD: median equivalent dose.

of the rectum in CS was about one-third of the prescribed dose. In contrast, when using the 3D-CRT modality, the dose is typically almost $0 \mathrm{~Gy}$. In this study, we considered the rectal dose in CS to be small enough to be negligible and did not consider it when calculating the BED for the rectum. It is possible that the total rectal dose may have been higher than our estimation. However, the incidence of rectal hemorrhage was comparable with or lower than those of previous studies using 3D-CRT (32-34).

Hematologic toxicities. Our results showed a relatively higher incidence of acute HT than previous reports of IMRT and 3D-CRT (Table VIII). One possible reason may be that 13 of the 30 patients had a low hemoglobin level $(<10 \mathrm{~g} / \mathrm{dl}$; already equivalent to Grade 2) before treatment. Furthermore, 5 of the 13 patients showed Grade 3 anemia during treatment. Another reason for this observation is as follows: in WPRT using TomoTherapy, a larger volume of pelvic bones was included in the lowdose area compared with other IMRT and 3D-CRT modalities, because TomoTherapy provides a continuous 360-degree beam to achieve optimal dose distribution and dose conformity. Some investigators have reported that $40 \%-60 \%$ of all the bone marrow is distributed in the pelvic bones, and that HT may be caused when dose volume parameters in pelvic bone marrow are V20>75\%$80 \%$ or $\mathrm{V} 10>90 \%$ (35-37). In this study, we prioritized dose sparing of the bowel over that of bone marrow, hence, the treatment plan did not have any constraints on the estimated dose to the bone marrow. Therefore, it is possible that a relatively large volume of bone marrow received a low dose, temporarily causing bone marrow suppression. Careful dose sparing of the bone marrow may be necessary to avoid bone marrow suppression when using TomoTherapy for WPRT. 

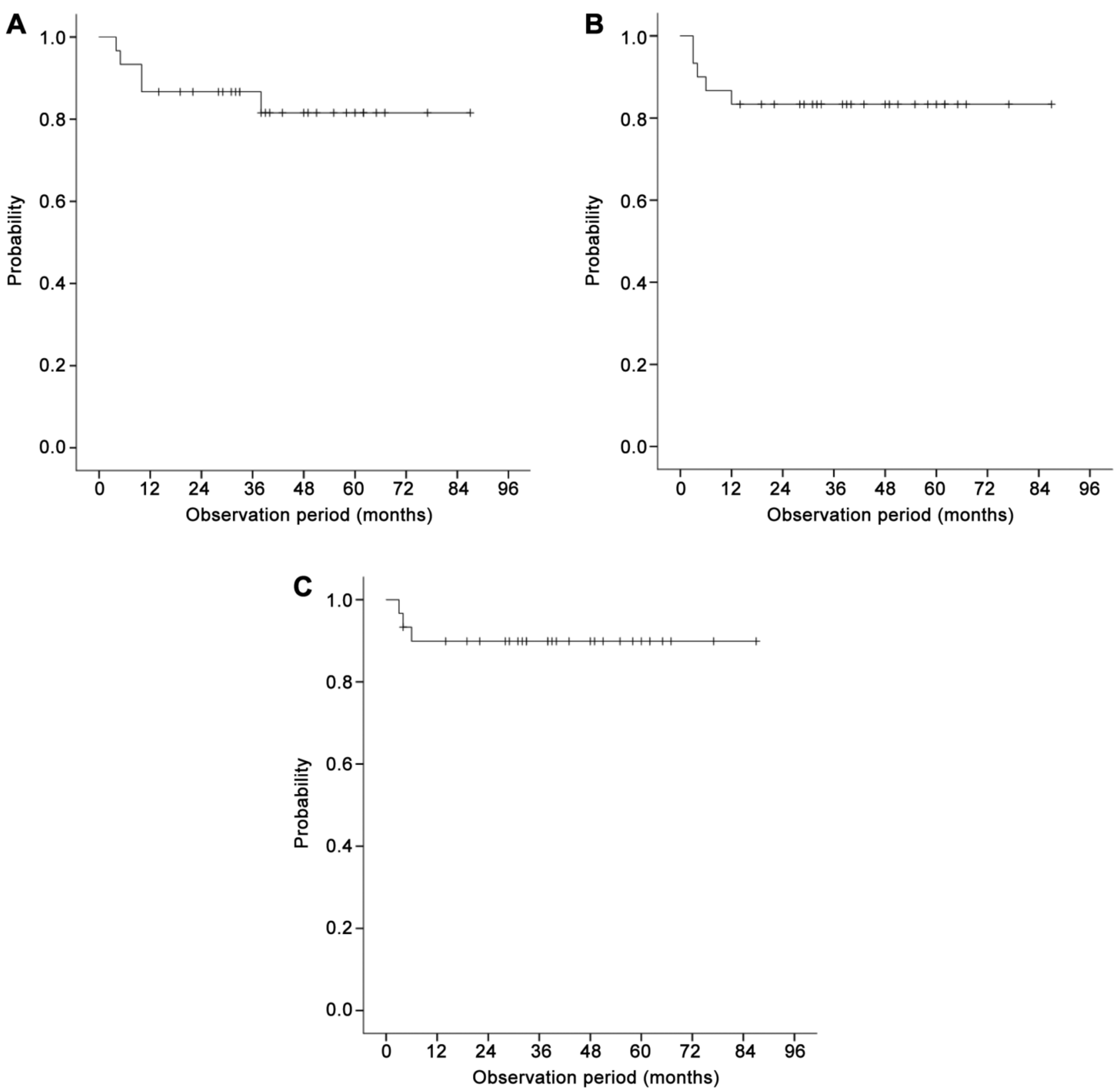

Figure 3. Clinical outcomes of the patients with cervical cancer after definitive radiation therapy. A) Overall survival. B) Disease-free survival. C) Local control.

Treatment delays. Treatment delays of $>56$ days have been associated with poor clinical outcomes (38-41). In our study, nine patients took $>56$ days to complete their treatments because they experienced Grade 3 HT. However, extended or longer treatment time ( $>56$ days) did not significantly affect OS, DFS, or LC. The longest treatment time among these 9 patients was 64 days $(n=2)$, which was only 8 days over 56 days. We considered such a short delay to have no significant effect on clinical outcome.
Validity/Appropriateness of IMRT for UCC. Some reports have described the risk of intra- and inter-fractional organ motion when using IMRT for UCC, such as that of the uterus, bladder, and rectum $(27,28,35)$. Concerning these dynamic changes of position and volume of organs, precise dose distribution by IMRT with the small margins applied in our patients may be subject to criticism. The following strategies were taken to address this issue: first, prior to the planning $\mathrm{CT}$, as well as daily treatments, patients were asked to 
Table V. Pattern of failure.

\begin{tabular}{|c|c|c|c|c|c|c|c|c|}
\hline Case & FIGO 2008 & Histopathology & $\begin{array}{c}\text { Total tumor } \\
\text { EQD2 } \\
(\alpha / \beta=10)\end{array}$ & $\begin{array}{c}\text { Local } \\
\text { progression }\end{array}$ & $\begin{array}{l}\text { Distance } \\
\text { metastases }\end{array}$ & $\begin{array}{l}\text { Progression } \\
\text { free survival } \\
\quad(\mathrm{mo})\end{array}$ & $\begin{array}{l}\text { Disease } \\
\text { status }\end{array}$ & $\begin{array}{c}\text { Overall } \\
\text { survival } \\
(\mathrm{mo})\end{array}$ \\
\hline 1 & IIIB & $\mathrm{SCC}$ & 66.7 & + & lung, liver & 2 & DOD & 4 \\
\hline 2 & IIB & MA & 69.4 & + & lung, liver & 3 & DOD & 10 \\
\hline 3 & IB & $\mathrm{Ca}$ & 61.3 & - & lung, liver, bone & 3 & DOD & 4 \\
\hline 4 & IIIB & MA & 70.9 & - & PAN, SCN & 12 & DOD & 36 \\
\hline 5 & IIIB & $\mathrm{SCC}$ & 65.8 & + & - & 2 & Alive with disease & 15 \\
\hline 6 & IVA & SCC & 69.3 & - & PAN & 60 & Alive without disease & 87 \\
\hline
\end{tabular}

mo: Months; SCC: squamous cell carcinoma; MA: mucinous adenocarcinoma; Ca: carcinoma; PAN: para-aortic lymph node metastasis; SCN: supraclavicular lymph node metastasis; DOD: died of disease. EQD2: median 2 Gy per fraction-equivalent dose of combined WPRT and HDRICBT to Point A $(\alpha / \beta=10)$. (EQD2) of combined WPRT and HDR-ICBT to Point $A(\alpha / \beta=10)$ and to the rectum $(\alpha / \beta=3)$ was $71.0 \mathrm{~Gy}$ (range=57.74$82.56 \mathrm{~Gy})$ and $65.4 \mathrm{~Gy}$ (range=56.96-72.9 Gy).

maintain an almost-full bladder and to ensure an empty rectum as described in Material and Methods. Second, in the contouring process, previously acquired contrast-enhanced CT images and MR images were fused to the planning CT images to delineate the GTV and CTV precisely, and in our treatment planning, steep dose gradients around GTV and uterus were avoided, allowing possible organ motion. Third, intra-fractional organ motion should be considered. Recent reports have evaluated precisely intra-fractional changes during radiotherapy of cervical cancer; Visser et al. reported that if the treatment plan can be delivered within 10 minutes, a $5 \mathrm{~mm}$ PTV margin for CTV cervix-uterus is enough to account for intra-fractional anatomical changes (42). Heijkoop et al. reported that intra-fractional cervix-uterus motion was up to 5-6 mm during their treatment time frame of 20.4 minutes (43). In our study, the PTV margins were 1 $\mathrm{cm}$ for cervical tumor and 5-7 $\mathrm{mm}$ around the uterus and parametrium. The treatment time was less than 7 minutes, including the MVCT scan. In reference to these reports mentioned above (42-44), the treatment planning of our study may be sufficient to afford intra-fractional movement of pelvic organs. Lastly, as inter-fractional motion, deformity, and regression of the target volume decreased the size of the uterus, daily changes in the bladder and rectum volume are included. With the TomoTherapy system, image registration between the daily-acquired MVCT and original treatmentplanning CT is required to perform RT. Schwarz et al. reported that one potential advantage of Helical TomoTherapy for IMRT delivery is the on-board imaging with daily MVCT scans. These improve daily setup and ensure that the pelvic target is within the PTV (36). In our clinical practice, radiation oncologists routinely check the inter-fractional motion and the dose distribution to target and OARs on MVCT immediately before irradiation. When the MVCT does not match the treatment planning isodose line, a new CT is immediately obtained to update the treatment
Table VI. Acute and late toxicities.

\begin{tabular}{|c|c|c|c|c|c|}
\hline \multirow[b]{2}{*}{$\begin{array}{l}\text { Acute toxicity } \\
\text { Hematology toxicity }(\mathrm{HT})\end{array}$} & \multicolumn{5}{|c|}{ Grade (n) } \\
\hline & 1 & 2 & 3 & 4 & 5 \\
\hline Anemia & 7 & 7 & 7 & - & - \\
\hline White blood cell decreased & 2 & 3 & 13 & 1 & - \\
\hline Neutrophil count decreased & 1 & 7 & 6 & 2 & - \\
\hline Platelet count decreased & 1 & 5 & 1 & - & - \\
\hline \multicolumn{6}{|l|}{ General conditions } \\
\hline Weight loss & 1 & 0 & 0 & - & - \\
\hline Edema & 2 & 1 & 0 & - & - \\
\hline Dermatitis and mucositis & 26 & 4 & 0 & 0 & 0 \\
\hline \multicolumn{6}{|l|}{ Gastrointestinal (GI) } \\
\hline Anorexia & 6 & 0 & 0 & 0 & 0 \\
\hline Diarrhea & 16 & 0 & 0 & - & - \\
\hline Nausea & 10 & 1 & - & - & - \\
\hline Rectal hemorrhage & 2 & 2 & 0 & 0 & 0 \\
\hline \multicolumn{6}{|l|}{ Genitourinary (GU) } \\
\hline Urinary frequency & 3 & 1 & - & - & - \\
\hline \multirow[t]{2}{*}{ Cystitis, non-infective } & 2 & 0 & 0 & 0 & 0 \\
\hline & \multicolumn{5}{|c|}{ Grade (n) } \\
\hline Late toxicity & 1 & 2 & 3 & 4 & 5 \\
\hline \multicolumn{6}{|l|}{ Gastrointestinal (GI) } \\
\hline Rectal hemorrhage & 0 & 2 & 0 & 0 & 0 \\
\hline
\end{tabular}

A sign dash (-) indicates that grade is not available.

planning. The mean re-planning in this study was one (range $=1-4)$ time. A new treatment plan was applied within 2 days at least.

For the future, some challenges remain to be solved: First, further consideration is needed for the control of mucinous adenocarcinoma. Both patients with this histology type had a poor outcome in our study, in line with previous reports (45-47). Okame et al. reported that radical hysterectomy 
Mukai et al: IMRT Using Central-shielding for Uterine Cervical Cancer

Table VII. Summary of published studies on TomoTherapy, IMRT and 3DCRT with CS for cervical cancer.

\begin{tabular}{lccccccccc}
\hline $\begin{array}{l}\text { Author } \\
\text { year }\end{array}$ & $\begin{array}{c}\text { Patients } \\
\text { [n })\end{array}$ & $\begin{array}{c}\text { Histology } \\
\text { ref }]\end{array}$ & FIGO stage & $\begin{array}{c}\text { Definitive RT } \\
(\%)\end{array}$ & RT technique & $\begin{array}{c}\text { RT dose } \\
(\mathrm{Gy})\end{array}$ & ICBT & $\begin{array}{c}\text { CTx } \\
(\%)\end{array}$ & $\begin{array}{c}\text { Disease } \\
\text { control (y) } \\
(\%)\end{array}$ \\
\hline
\end{tabular}

TomoTherapy study

\begin{tabular}{|c|c|c|c|c|c|c|c|c|c|c|}
\hline $\begin{array}{l}\text { Chen-His H } \\
\text { (5) }\end{array}$ & 10 & $\begin{array}{l}70 \% \\
\text { SCC }\end{array}$ & II B- III B & $100 \%$ & $\begin{array}{c}\text { Helical } \\
\text { Tomotherapy }\end{array}$ & WP 50.4 & $\begin{array}{c}30 \mathrm{~Gy} / 6 \mathrm{fr} \\
\mathrm{Gy} / 28 \mathrm{fr}\end{array}$ & $100 \%$ & $\begin{array}{c}\text { DFS } \\
77 \%(2 \mathrm{y})\end{array}$ & $67 \%(2 y)$ \\
\hline $\begin{array}{l}\text { Albert J } \\
2010(6)\end{array}$ & 15 & $\begin{array}{l}86 \% \\
\text { SCC }\end{array}$ & I B-IV A & $100 \%$ & $\begin{array}{c}\text { Helical } \\
\text { Tomotherapy }\end{array}$ & WP 50.4 & $\begin{array}{l}6.5 \mathrm{~Gy} / \mathrm{fr} \\
\mathrm{Gy} / 28 \mathrm{fr}\end{array}$ & $86.7 \%$ & $\begin{array}{c}\text { PFS } \\
80 \%(3 \mathrm{y})\end{array}$ & NA \\
\hline $\begin{array}{l}\text { Y.J Kim } \\
2013(7)\end{array}$ & 26 & $\begin{array}{l}92 \% \\
\text { SCC }\end{array}$ & II A-IV B & $100 \%$ & $\begin{array}{c}\text { Helical } \\
\text { Tomotherapy }\end{array}$ & WP 39.6-54 Gy & $30 \mathrm{~Gy} / 6 \mathrm{fr}$ & NA. & NA & $65 \%(3 \mathrm{y})$ \\
\hline
\end{tabular}

IMRT study

\begin{tabular}{|c|c|c|c|c|c|c|c|c|c|c|}
\hline $\begin{array}{l}\text { Chien C } \\
2011(1)\end{array}$ & 109 & $\begin{array}{l}89 \% \\
\text { SCC }\end{array}$ & II B-III A & $100 \%$ & IMRT & WP 45-54 Gy & 20-33.5 Gy & $\begin{array}{l}100 \% \\
\text { CDDP }\end{array}$ & $\begin{array}{c}\text { DFS } \\
67.6 \%(3 \mathrm{y})\end{array}$ & $\begin{array}{l}78.2 \% \\
(3 \mathrm{y})\end{array}$ \\
\hline $\begin{array}{l}\text { Shang-wen C } \\
\text { (26) }\end{array}$ & 320 & $\begin{array}{l}90 \% \\
\text { SCC }\end{array}$ & I B-III B & $100 \%$ & $\begin{array}{l}\text { IMRT }(n=237), \\
\text { 3DCRT }(n=83)\end{array}$ & WP 45 Gy & $24 \mathrm{~Gy} / 4 \mathrm{fr}$ & NA & $\begin{array}{c}\text { DFS } \\
78 \%(3 \mathrm{y})\end{array}$ & NA \\
\hline
\end{tabular}

3D-CRT with CS study

\begin{tabular}{llllllllll}
\hline $\begin{array}{l}\text { Toita T } \\
(12)\end{array}$ & 88 & $\begin{array}{l}100 \% \\
\text { SCC }\end{array}$ & $71.5 \%>$ IIIB & $100 \%$ & 3DCRT & $\begin{array}{c}\text { WP50 Gy } \\
\text { with CS }\end{array}$ & 24 Gy/6 fr & $0 \%$ & $\begin{array}{c}\text { LC } \\
87 \%\end{array}$ \\
\hline
\end{tabular}

TomoTherapy with CS study

\begin{tabular}{|c|c|c|c|c|c|c|c|c|c|c|}
\hline Our study & 30 & $\begin{array}{l}83.3 \% \\
\text { SCC }\end{array}$ & $\begin{array}{l}40 \% 1 \mathrm{~b}-2 \mathrm{~b} \\
60 \% 3 \mathrm{a}-4 \mathrm{~b}\end{array}$ & $100 \%$ & $\begin{array}{c}\text { Helical } \\
\text { Tomotherapy }\end{array}$ & $\begin{array}{l}\text { WP } 50.4 \text { Gy } \\
\text { with CS }\end{array}$ & $\begin{array}{l}24.3 \mathrm{~Gy} / \\
4-5 \mathrm{fr}\end{array}$ & $73.3 \%$ & $\begin{array}{c}\text { PFS } \\
89.9 \%(2 \mathrm{y})\end{array}$ & $\begin{array}{c}86.3 \% \\
(2 \mathrm{y})\end{array}$ \\
\hline
\end{tabular}

RT: Radiation therapy; FIGO: international federation of gynecology and obstetrics; ICBT: intra-cavity brachytherapy; CTx: chemotherapy; OS: overall survival; SCC: squamous cell carcinoma; DFS: disease-free survival; PFS: progression-free survival; NA: not available; WP: whole pelvic radiation therapy; IMRT: intensity-modulated radiation therapy; 3DCRT: three-dimensional radiation therapy; CS: central shielding; y: year; m: months.

improved the clinical outcome of patients with mucinous adenocarcinoma compared with RT (42). Treatment options for this disease type should be carefully considered. Second, treatment options for poor responders to WPRT preceding ICBT should be reconsidered. In these patients, the reduction in tumor volume was insufficient and the tandem applicators could not be inserted into the external uterine orifice. It was difficult to start WPRT-CS, which reduces the dose to the tumor, while the rectal dose increases up to $50 \mathrm{~Gy}$. Even if the ICBT could be started after 50 Gy of WPRT, it was delivered fewer than 5 times, and usually limited to 3 times, to avoid excess dose to the rectum. There were three such cases in the current study, one of which developed local recurrence, suggesting insufficient dose delivery to the tumor. In such cases, image guided brachytherapy (IGBT) utilizing intracavitary and interstitial approach may represent a potential treatment strategy to deliver enough dose to the tumor without increasing the dose to OARs $(48,49)$.

The limitations of our study were that the number of patients was small and that the median follow-up time was relatively short (38.5 months). In addition, we did not
Table VIII. Summary of published studies on acute hematology toxicity of IMRT and $3 D$-CRT for cervical cancer.

\begin{tabular}{lccc}
\hline $\begin{array}{l}\text { Acute } \\
\text { hematology } \\
\text { toxicity }\end{array}$ & IMRT $(1,5,8)$ & 3D-CRT $(8,25,39)$ & Our study \\
\hline Anemia & G3-4: $2 \%$ & $>$ G3-4: 4.6-10\% & G3: $23 \%$ \\
& G4: 0 \\
$\begin{array}{l}\text { White blood cell } \\
\text { decreased }\end{array}$ & G3: 22-30\% & $>$ G3-4: 23.1-26\% & G3: $43 \%$ \\
$\begin{array}{l}\text { Neutrophil count } \\
\text { decreased }\end{array}$ & G2 $>40 \%$ & $>$ G3-4: $16 \%$ & G2 2 -3.3 $43 \%$ \\
$\begin{array}{l}\text { Platelet count } \\
\text { decreased }\end{array}$ & G2: 3-40\% & G2: $23 \%$ & G2: $2: 16.6 \%$ \\
\hline
\end{tabular}

IMRT: Intensity-modulated radiation therapy; 3D-CRT: threedimensional conformal radiation therapy.

evaluate the dose distribution to OARs such as rectum and bone marrow in this study. Further studies are required to determine the indications, long-term efficacy, and 
relationship between possible late toxicities and dose distribution to the corresponding/counterpart OARs.

\section{Conclusion}

In the present study, the combination of IMRT consisting of WPRT and WPRT-CS using TomoTherapy and HDR-ICBT was feasible and resulted in good disease control and tolerance rates for UCC patients. This method can replace 3D-CRT modalities and may become the standard RT strategy for UCC in Asian countries in the near future, given its low incidence of late GI and GU toxicities.

\section{Conflicts of Interest}

None of the Authors have any conflicts of interest associated with this study.

\section{Authors' Contributions}

Conceptualization, analysis and writing - original draft preparation: Y.M., M.O. Writing - review and editing: all co-authors.

\section{Disclosure}

This paper was presented at the ESTRO meets Asia 2018 in Singapore as conference talk with interim findings.

\section{References}

1 Herrera FG, Callaway S, Delikgoz-Soykut E, Coskun M, Porta L, Meuwly JY, Soares-Rodrigues J, Heym L, Moeckli R and Mahmut Ozsahin M: Retrospective feasibility study of simultaneous integrated boost in cervical cancer using Tomotherapy: the impact of organ motion and tumor regression. Radiat Oncol 8: 5, 2013. PMID: 23286694. DOI: 10.1186/1748717X-8-5

2 Marnitz S, Köhler C, Burova E, Wlodarczyk W, Jahn U, Grün A, Budach V and Stromberger C: Helical tomotherapy with simultaneous integrated boost after laparoscopic staging in patients with cervical cancer: analysis of feasibility and early toxicity. Int J Radiat Oncol Biol Phys 82(2): e137-143, 2012. PMID: 21600704. DOI: 10.1016/j.ijrobp.2010.10.066

3 Ogino I, Kitamura T, Okamoto N, Yamasita K, Aikawa Y, Okajima $\mathrm{H}$ and Matsubara S: Late rectal complication following high dose rate intracavitary brachytherapy in cancer of the cervix. Int J Radiat Oncol Biol Phys 31: 5, 1995. DOI: 10.1016/0360-3016(94)00547-8

4 Chen CC, Lin JC, Jan JS, Shih CH and Lily W: Definitive intensity-modulated radiation therapy with concurrent chemotherapy for patients with locally advanced cervical cancer. Gynecol Oncol 122(1): 9-13, 2011. PMID: 21514629. DOI: 10.1016/j.ygyno.2011.03.034

5 Lee J, Lin JB, Sun FJ, Chen YJ, Chang CL, Jan YT and Wu MH: Safety and efficacy of semiextended field intensitymodulated radiation therapy and concurrent cisplatin in locally advanced cervical cancer patients: An observational study of 10- year experience. Medicine 96(10): e6158, 2017. PMID: 28272204. DOI: 10.1097/MD.0000000000006158

6 Zhang G, He F, Fu C, Zhang Y, Yang Q, Wang J and Cheng Y: Definitive extended field intensity-modulated radiotherapy and concurrent cisplatin chemosensitization in the treatment of IB2IIIB cervical cancer. J Gynecol Oncol 25(1): 14-21, 2014. PMID: 24459576. DOI: 10.3802/jgo.2014.25.1.14

7 Kidd EA, Siegel BA, Dehdashti F, Rader JS, Mutic S, Mutch DG, Powell MA and Grigsby PW: Clinical outcomes of definitive intensity-modulated radiation therapy with fluorodeoxyglucose-positron emission tomography simulation in patients with locally advanced cervical cancer. Int J Radiat Oncol Biol Phys 77(4): 1085-1091, 2010. PMID: 19880262. DOI: $10.1016 /$ j.ijrobp.2009.06.041

8 Hsieh CH, Wei MC, Lee HY, Hsiao SM, Chen CA, Wang LY, Hsieh YP, Tsai TH, Chen YJ and Shueng PW: Whole pelvic helical tomotherapy for locally advanced cervical cancer: technical implementation of IMRT with helical tomotherapy. Radiat Oncol 4: 62, 2009. PMID: 20003321. DOI: 10.1186/ 1748-717X-4-62

9 Chang AJ, Richardson S, Grigsby PW and Schwarz JK: Splitfield helical tomotherapy with or without chemotherapy for definitive treatment of cervical cancer. Int J Radiat Oncol Biol Phys 82(1): 263-269, 2012. PMID: 21167656. DOI: 10.1016/ j.ijrobp.2010.09.049

10 Kim YJ, Kim JY, Yoo SH, Min BJ, Chung KZ, Seo SS, Kang SB, Lim MC, Hwang JH, Yoo HJ and Park SY: High control rate for lymph nodes in cervical cancer treated with high-dose radiotherapy using helical tomotherapy. Technol Cancer Res Treat 12(1): 45-51, 2013. PMID: 22905806. DOI: 10.7785/ tcrt.2012.500252

11 Hui B, Zhang Y, Shi F, Wang J, Wang T, Wang J, Yuan W, Li Y and Liu Z: Association between bone marrow dosimetric parameters and acute hematologic toxicity in cervical cancer patients undergoing concurrent chemoradiotherapy: comparison of three-dimensional conformal radiotherapy and intensitymodulated radiation therapy. Int J Gynecol Cancer 24(9): 16481652, 2014. PMID: 25275663. DOI: 10.1097/IGC. 0000000000000292

12 Toita T, Kato S, Niibe Y, Ohno T, Kazumoto T, Kodaira T, Kataoka M, Shikama N, Kenjo M, Tokumaru S, Yamauchi C, Suzuki O, Sakurai H, Numasaki H, Teshima T, Oguchi M, Kagami Y, Nakano T, Hiraoka M and Mitsuhashi N: Prospective multi-institutional study of definitive radiotherapy with high-doserate intracavitary brachytherapy in patients with nonbulky $(<4-\mathrm{cm})$ stage I and II uterine cervical cancer (JAROG0401/JROSG04-2). Int J Radiat Oncol Biol Phys 82(1): e49-56, 2012. PMID: 21470794. DOI: 10.1016/j.jirobp.2011.01.022

13 Toita T, Kakinohana Y, Ogawa K, Adachi G, Moromizato H, Nagai Y, Maehama T, Sakumoto K, Kanazawa K and Murayama $\mathrm{S}$ : Combination external beam radiotherapy and high-dose-rate intracavitary brachytherapy for uterine cervical cancer: analysis of dose and fractionation schedule. Int J Radiat Oncol Biol Phys 56(5): 1344-1353, 2003. PMID: 12873679. DOI: 10.1016/s03603016(03)00288-8

14 Japan Clinical Oncology Group; Toita T, Ohno T, Kaneyasu Y, Uno T, Yoshimura R, Kodaira T, Furutani K, Kasuya G, Ishikura $\mathrm{S}$, Kamura $\mathrm{T}$ and Hiraoka M: A consensus-based guideline defining the clinical target volume for pelvic lymph nodes in external beam radiotherapy for uterine cervical cancer. Jpn J Clin 
Oncol 40(5): 456-463, 2010. PMID: 20133334. DOI: 10.1093/ jjco/hyp 191

15 Toita T, Ohno T, Kaneyasu Y, Kato T, Uno T, Hatano K, Norihisa Y, Kasamatsu T, Kodaira T, Yoshimura R, Ishikura S, Hiraoka M and JCOG Radiation Therapy Study Group: A consensus-based guideline defining clinical target volume for primary disease in external beam radiotherapy for intact uterine cervical cancer. Jpn J Clin Oncol 41(9): 1119-1126, 2011. PMID: 21875938. DOI: $10.1093 / \mathrm{jjco} / \mathrm{hyr} 096$

16 Roeske JC, Lujan A, Rotmensch J, Waggoner SE, Yamada D and Mundt AJ: Intensity-modulated whole pelvic radiation therapy in patients with gynecologic malignancies. Int J Radiat Oncol Biol Phys 48(5): 1613-1621, 2000. PMID: 11121668. DOI: 10.1016/s0360-3016(00)00771-9

17 Taylor A, Rockall AG and Powell ME: An atlas of the pelvic lymph node regions to aid radiotherapy target volume definition. Clin Oncol (R Coll Radiol) 19(7): 542-550, 2007. PMID: 17624745. DOI: $10.1016 /$ j.clon.2007.05.002

18 Klopp A: A randomized phase III study of standard $v s$. IMRT pelvic radiation for post-operative treatment of endometrial and cervical cancer (TIME-C)-RTOG CCOP Study (RTOG 1203). Available at: https://www.google.com/url?sa=t\&rct=j\&q=\&esrc= s\&source=web\&cd=\&ved=2ahUKEwiC8_echs_qAhUjtnEKHX4 zBtkQFjABegQIAhAB\&url=https\%3A\%2F\%2Fwww.nrgoncolo gy.org $\% 2$ FClinical-Trials $\% 2$ FProtocol $\% 2$ Frtog-1203\%3Ffilter\% 3Drtog-1203\&usg=AOvVaw2KZDK68gvex 8cN67LWyS6P [Last accessed July 15, 2020]

19 Image guided intensity modulated external beam radiochemotherapy and MRI based adaptive Brachytherapy in locally advanced cervical cancer (EMBRACE). Available at: https://www.embracestudy.dk/Public/Default.aspx?main=1\&sub= 12\&embrace=embrace [Last accessed July 14, 2020]

20 Ebina Y, Yaegashi N, Katabuchi H, Nagase S, Udagawa Y, Hachisuga T, Saito T, Mikami M, Aoki Y and Yoshikawa H: Japan Society of Gynecologic Oncology guidelines 2011 for the treatment of uterine cervical cancer. Int J Clin Oncol 20(2): 240248, 2015. PMID: 25800808. DOI: 10.1007/s10147-015-0806-7

21 Chun M, Kang S, Ryu H, Chang K, Oh Y, Ju H and Lee E: Modified partial hyprfractionation in radiotherapy for bulky uterine cervical cancer: reduction of overall treatment time. Int J Radiat Oncol Biol Phys 47(4): 973-977, 2000. PMID: 10863067. DOI: 10.1016/s0360-3016(00)00539-3

22 Ohno T, Nakano T, Kato S, Koo CC, Chansilpa Y, Pattaranutaporn P, Calaguas MJC, Reyes RHL, Zhou B, Zhou J, Susworo R, Supriana N, Dung TA, Ismail F, Sato S, Suto H, Nakamura YK and Tsujii H: Accelerated hyperfractionated radiotherapy for cervical cancer: multi-institutional prospective study of forum for nuclear cooperation in Asia among eight Asian countries. Int J Radiat Oncol Biol Phys 70(5): 1522-1529, 2008. PMID: 17919839. DOI: 10.1016/j.ijrobp.2007.08.038

23 Nag S, Erickson B, Thomadsen B, Orton C, Demanes JD and Petereit D: The American Brachytherapy Society recommendations for high-dose-rate brachytherapy for carcinoma of the cervix. Int J Radiat Oncol Biol Phys 48(1): 201-211, 2000. PMID: 10924990. DOI: 10.1016/s03603016(00)00497-1

24 Jouglar E, Thomas L, Rochefordière Al, Noël G, Blanc-Onfroy ML, Delpon G, Campion L and Mahé MA: Toxicity and early clinical outcomes in cervical cancer following extended field helical tomotherapy to para-aortic lymph nodes. Cancer
Radiother 20(8): 794-800, 2016. PMID: 28270323. DOI: 10.1016/j.canrad.2016.06.007

25 Marnitz S, Lukarski D, Köhler C, Wlodarczyk W, Ebert A, Budach V, Schneider A, Stromberger C: Helical tomotherapy versus conventional IMRT for primary chemoradiation in cervical cancer patients: an intraindividual comparison. Int J Radiat Oncol Biol Phys 81(2): 424-430, 2011. PMID: 20864270. DOI: $10.1016 /$ j.jjrobp.2010.06.005

26 Tamaki T, Hirai R, Igari M, Kumazaki Y, Noda SE, Suzuki Y and Kato S: Dosimetric comparison of three-dimensional conformal radiotherapy versus volumetric-arc radiotherapy in cervical cancer treatment: applying the central-shielding principle to modern technology. J Radiat Res 59(5): 639-648, 2018. PMID: 30053184. DOI: 10.1093/jrr/rry054

27 Ferrigno R, Santos A, Martins LC, Weltman E, Chen MJ, Sakuraba R, Lopes CP and Cruz JC: Comparison of conformal and IMRT techniques for treatment of pelvic tumors. Analysis of acute toxicity. Radiat Oncol 5: 117, 2010. PMID: 21156076. DOI: $10.1186 / 1748-717 \mathrm{X}-5-117$

28 Chen SW, Liang JA, Hung YC, Yeh LS, Chang WC, Lin WC and Chien CR: Does initial 45Gy of pelvic intensity-modulated radiotherapy reduce late complications in patients with locally advanced cervical cancer? A cohort control study using definitive chemoradiotherapy with high-dose rate brachytherapy. Radiol Oncol 47(2): 176-184, 2013. PMID: 23801915. DOI: 10.2478/raon-2013-0011

29 Lee S, Suh CO, Chung EJ and Kim GE: Dose optimization of fractionated external radiation and high-dose-rate intracavitary brachytherapy for FIGO stage IB uterine cervical carcinoma. Int J Radiat Oncol Biol Phys 52(5): 1338-1344, 2002. PMID: 11955747. DOI: 10.1016/s0360-3016(01)02821-8

30 Huang EY, Lin H, Hsu HC, Wang CJ, Chen HC, Sun LM and Hsiung CY: High external parametrial dose can increase the probability of radiation proctitis in patients with uterine cervix cancer. Gynecol Oncol 79(3): 406-410, 2000. PMID: 11104610. DOI: $10.1006 /$ gyno.2000.5997

31 Chen SW, Liang JA, Yang SN, Liu RT and Lin FJ: The predication of late rectal complications following the treatment of uterine cervical cancer by high-dose-rate brachytherapy. Int J Radiat Oncol Biol Phys 47(4): 955-961, 2000. PMID: 10863065. DOI: 10.1016/s0360-3016(00)00559-9

32 Nakano T, Kato S, Ohno T, Tsujii H, Sato S, Fukuhisa K and Arai T: Long-term results of high-dose rate intracavitary brachytherapy for squamous cell carcinoma of the uterine cervix. Cancer 103(1): 92-101, 2005. PMID: 15540233. DOI: 10.1002/ cncr.20734

33 Tokumaru S, Toita T, Oguchi M, Ohno T, Kato S, Niibe Y, Kazumoto T, Kodaira T, Kataoka M, Shikama N, Kenjo M, Yamauchi C, Suzuki O, Sakura i H, Teshima T, Kagami Y, Nakano T, Hiraoka M, Mitsuhashi N and Kudo S: Insufficiency fractures after pelvic radiation therapy for uterine cervical cancer: an analysis of subjects in a prospective multiinstitutional trial, and cooperative study of the Japan Radiation Oncology Group (JAROG) and Japanese Radiation Oncology Study Group (JROSG). Int J Radiat Oncol Biol Phys 84(2): e195-200, 2012. PMID: 22583605. DOI: 10.1016/j.ijrobp. 2012.03.042

34 Ohno T, Kato S, Sato S, Fukuhisa K, Nakano T, Tsujii H and Arai T: Long-term survival and risk of second cancers after radiotherapy for cervical cancer. Int J Radiat Oncol Biol Phys 
69(3): 740-745, 2007. PMID: 17889265. DOI: 10.1016/j.ijrobp. 2007.04 .028

35 Platta CS, Bayliss A, McHaffie D, Tome WA, Straub MR and Bradley KA: A dosimetric analysis of tomotherapy based intensity modulated radiation therapy with and without bone marrow sparing in gynecologic malignancies. Technol Cancer Res Treat 12(1): 19-29, 2013. PMID: 22974331. DOI: $10.7785 /$ tcrt 2012.500300

36 Hui B, Zhang Y, Shi F, Wang J, Wang T, Wang J, Yuan W, Li Y and Liu Z: Association between bone marrow dosimetric parameters and acute hematologic toxicity in cervical cancer patients undergoing concurrent chemoradiotherapy. Int J Gynecol Cancer 24(9): 1648-1652, 2014. PMID: 25275663. DOI: $10.1097 /$ IGC.0000000000000292

37 Albuquerque K, Giangreco D, Morrison C, Siddiqui M, Sinacore $\mathrm{J}$, Potkul R and Roeske J: Radiation-related predictors of hematologic toxicity after concurrent chemotradiation for cervical cancer and implications for bone marrow-sparing pelvic IMRT. Int J Radiat Oncol Biol Phys 79(4): 1043-1047, 2011. PMID: 20471182. DOI: 10.1016/j.ijrobp.2009.12.025

38 Zaki M, Dominello M, Morris R and Miller S: Factors predictive of protracted course of radiation therapy in patients treated with definitive chemoradiation for cervical cancer. Cureus 8(4): e558, 2016. PMID: 27182472. DOI: 10.7759/cureus.558

39 Chen SW, Liang JA, Yang SN, Ko HL and Lin FJ: The adverse effect of treatment prolongation in cervical cancer by high-doserate intracavitary brachytherapy. Radiother Oncol 67(1): 69-76, 2003. PMID: 12758242. DOI: $10.1016 / \mathrm{s} 0167-8140(02) 00439-5$

40 Monk BJ, Tian C, Rose PG and Lanciano R: Which clinical/pathologic factors matter in the era of chemoradiation as treatment for locally advanced cervical carcinoma? Analysis of two gynecologic oncology group (GOG) trials. Gynecol Oncol 105(2): 427-433, 2007. PMID: 17275889. DOI: 10.1016/j. ygyno.2006.12.027

41 Perez CA, Grigsby PW, Castro-Vita H and Lockett MA: Carcinoma of the uterine cervix. I. Impact of prolongation of overall treatment time and timing of brachytherapy on outcome of radiation therapy. Int J Radiat Oncol Biol Phys 32(5): 1275-1288, 1995. PMID: 7635767. DOI: 10.1016/0360-3016(95)00220-S

42 Visser J, Boer P, Crama KF, Kesteren Z, Rasch CRN, Stalpers LJA and Bel A: Dosimetric comparison of library of plans and online MRI-guided radiotherapy of cervical cancer in the presence of intrafraction anatomical changes. Radiat Oncol 14(1): 126, 2019. PMID: 31300000. DOI: 10.1186/s13014-019-1322-0
43 Heijkoop ST, Langerak TR, Quint S, Mens JWM, Zolnay AG, Heijmen BJM and Hoogeman MS: Quantification of intrafraction changes during radiotherapy of cervical cancer assessed with pre- and post-fraction Cone Beam CT scans. Radiother Oncol 117(3): 536-534, 2015. PMID: 26409830. DOI: 10.1016/ j.radonc.2015.08.034

44 Schwarz JK, Wahab S and Grigsby PW: Prospective phase I-II trial of helical tomotherapy with or without chemotherapy for postoperative cervical cancer patients. Int J Radiat Oncol Biol Phys 81(5): 1258-1263, 2011. PMID: 20932657. DOI: 10.1016/ j.ijrobp.2010.07.038

45 Okame S, Kojima A, Teramoto N, Shiroyama Y, Yokoyama T, Takehara $\mathrm{K}$ and Nogawa $\mathrm{T}$ : Type $\mathrm{C} 2$ radical hysterectomy may improve outcomes of locally advancedmucinous adenocarcinoma of the uterine cervix. Int J Clin Oncol 21(4): 723-729, 2016. PMID: 26694814. DOI: 10.1007/s10147-015-0939-8

46 Vinh-Hung V, Bourgain C, Vlastos G, Cserni G, Ridder MD, Storme G and Vlastos AT: Prognostic value of histopathology and trends in cervical cancer: a SEER population study. BMC Cancer 7: 164, 2007. PMID: 17718897. DOI: 10.1186/14712407-7-164

$47 \mathrm{Li}$ XY, Liu L, Xie XM and Zhou C: The role of raltitrexed/cisplatin with concurrent radiation therapy in treating advanced cervical cancer. Eur Rev Med Pharmacol Sci 18(22): 3491-3496, 2014. PMID: 25491626.

48 Nemoto-Murofushi K, Yoshioka Y, Ishikawa H, Sumi M, Okumura T, Oguchi M and Sakurai H: Clinical outcomes of patients with asymmetrical cervical cancer treated with various high-dose-rate brachytherapy techniques. Anticancer Res 40(2): 999-1006, 2020. PMID: 32014945. DOI: 10.21873/anticanres. 14034

49 Chen SW, Liang JA, Hung YC, Yeh LS, Chang WC, Lin WC and Chang YY: Effectiveness of image-guided brachytherapy in patients with locally advanced cervical squamous cell carcinoma receiving concurrent chemoradiotherapy. Anticancer Res 39(6): 3015-3024, 2019. PMID: 31177143. DOI: 10.21873/anticanres. 13434

Received June 25, 2020

Revised July 14, 2020

Accepted July 15, 2020 